\title{
TOMAR EL PORTANTE NO ES SIMPLEMENTE 'MARCHARSE': REFLEXIONES SOBRE LA DEFINICIÓN DE LAS UNIDADES FRASEOLÓGICAS IDIOMÁTICAS EN LOS DICCIONARIOS DESDE EL PUNTO DE VISTA DE LA PRAGMÁTICA
}

Palabras clave: fraseografía, pragmática, interacción, modalidad, ejemplificación, corpus

\section{Introducción}

Las locuciones o unidades fraseológicas idiomáticas se caracterizan por su semantismo difuso, complejo y, en gran parte, potencial. Por esta razón, su definición correcta y precisa representa un reto para todo fraseógrafo.

A partir de la experiencia que estamos reuniendo con la elaboración de un Diccionario español-alemán de locuciones del español de España (DEALEE), en el presente artículo nos proponemos tratar los problemas esenciales con que topa el fraseógrafo a la hora de definir estas unidades. En general, podemos afirmar que, desde un punto de vista semántico-pragmático, la mayor dificultad radica en explicitar una información que en realidad sólo aflora en el lenguaje de modo implícito. Dado que nuestro diccionario es español-alemán, también tendremos en cuenta aspectos relacionados con este par de lenguas.

Tanto en nuestro trabajo fraseográfico como en el presente artículo nos servimos ante todo de las posibilidades de análisis que ofrece la lingüística pragmática; a lo largo de las siguientes páginas iremos exponiendo las razones que nos han motivado a tomar esta decisión. Ello no implica, no obstante, que dejemos de considerar otras teorías, de modo que, en algún que otro caso, en la elaboración del DEALEE también nos apoyamos en el cognitivismo, el formalismo, la semiótica, la sociolingüística y/o la teoría lexicográfica, por nombrar sólo algunas de las subdisciplinas lingüísticas a que el fraseógrafo puede y debería recurrir.

\section{Características del Diccionario español-alemán de locuciones del español de España de Colonia/Hamburgo}

Concebimos el diccionario que estamos elaborando ${ }^{1}$ como una obra de descodificación dirigida al público germanohablante; ello significa que pretendemos ofrecer res-

La mayoría de los redactores del DEALEE están vinculados a la Universidad de Ciencias Aplicadas de Colonia (Fachhochschule Köln); también contamos con colaboradoras de la Universidad de Bonn y de la Universidad de Viena. La publicación de nuestro diccionario está prevista en la editorial Buske de Hamburgo para el año 2015 aproximadamente: de ahí que hablemos del diccionario «de Colonia/Hamburgo» (véase Beßler et al., 2009). 
puestas al usuario, al cual se le han planteado interrogantes sobre el significado de una locución determinada en una lengua que no es la suya materna. Por esta razón, una de nuestras tareas fundamentales es la reflexión sobre el significado de las locuciones y la determinación y formulación del mismo, tema que constituye el objeto de este artículo. En este sentido, nuestro trabajo fraseográfico, esto es, la perspectiva de descodificación que hemos adoptado, nos hace compartir muchos objetivos con la fraseografía monolingüe.

\section{Aspectos semántico-pragmáticos de las unidades fraseológicas idiomáticas}

\subsection{Qué es una locución}

En la investigación de los sistemas fraseológicos de las lenguas cabe distinguir dos enfoques esencialmente distintos, si bien no siempre fácilmente separables: o bien se estudia la fraseología en sentido lato, campo que abarca refranes, fórmulas rutinarias, frases proverbiales, locuciones, frases célebres, etc., o bien se considera el sistema fraseológico en sentido estricto, el cual se reduce entonces a las locuciones, cuya principal característica que las diferencia de otras unidades de la fraseología en sentido lato es la llamada idiomaticidad.

A continuación citamos una definición de locución, término que consideramos sinónimo al de unidad fraseológica idiomática, formulada por nosotros mismos en Beßler et al. (2009), ${ }^{2}$ que se inspira, en el plano deductivo, en los estudios de diversos fraseólogos -entre otros, Ruiz (1997: 74 y 99) y Seco et al. (2004: XII)-, y se ajusta, en el plano inductivo, a la experiencia y a los criterios que surgen a partir de la elaboración del DEALEE: por locución entendemos una «agrupación más o menos fija de palabras que asume o bien una función gramatical determinada (nominal, adjetiva, verbal, etc.) en la oración (que puede corresponder a la oración entera) o bien una función pragmática o de conexión en el texto y cuyo significado no puede deducirse necesariamente de los significados de sus componentes» (Beßler et al., 2009). ${ }^{3}$

En la teoría semiótica se considera que una locución es un supersigno (cf. Grzybek, 2007: 192-193), dado el proceso de lexicalización y de transposición semántica que ha sufrido el grupo de palabras como tal.

2 En la publicación en línea Beßler et al. (2009) el lector interesado encontrará un glosario con algunos de los términos que utilizamos en nuestro proyecto como herramientas de análisis (fraseografía, diccionario pasivo, lema, forma citativa, etc.) junto con una definición de los mismos. Por cuestiones de espacio, no repetiremos aquí dichas definiciones.

3 Obsérvese, a partir de nuestra definición, que a la hora de determinar la categoría gramatical de una locución trabajamos con criterios funcionales, discursivos y textuales, pero no formalistas. De acuerdo con criterios funcionales, una unidad del tipo para sus adentros es adverbial, puesto que puede ser sustituida por un adverbio, mientras que desde el punto de vista formalista es prepositiva, puesto que su núcleo sintáctico es una preposición. No obstante, nos parece interesante mencionar que Bosque / Gutiérrez-Rexach (2009: 153), en sus Fundamentos de sintaxis formal, también consideran, al igual que nosotros, que una locución es una pieza léxica y la observan según su función dentro de la estructura de la oración, de modo que la unidad para sus adentros, en un libro de análisis formalista cien por cien, es considerada desde el punto de vista funcional: «para mis / tus / sus adentros está en el léxico como una sola pieza: una locución adverbial, por tanto, un adverbio» (Bosque / Gutiérrez-Rexach, 2009: 153). El tema de la clasificación de las locuciones es complejo; nuestros criterios de cara a la elaboración del DEALEE los hemos expuesto en parte en Torrent-Lenzen (en prensa/a) y en Torrent-Lenzen (2009/b), pero tenemos la intención de dedicar un artículo aparte a este aspecto crucial. 


\subsection{La idiomaticidad}

Las locuciones, así pues, son signos lingüísticos que denotan de manera indirecta (cf. Dobrovol'skij, 1988: 62): utilizamos una cadena de palabras para transmitir un significado que no es el de la cadena de palabras propiamente dicho (esto es, decimos Estoy hasta las narices cuando en realidad no estamos hablando de nariz alguna). El fenómeno por el cual una cadena de palabras no puede deducirse a partir del significado de sus componentes se denomina idiomaticidad. En Torrent-Lenzen / Uría Fernández (2009: 4) definimos idiomaticidad de la siguiente manera:

La idiomaticidad es un fenómeno por el cual sólo es posible entender el verdadero significado de una construcción sintagmática en un cotexto y contexto concretos si ésta se concibe como un todo, o bien porque su significado global es el resultado de un proceso diacrónico de transposición semántica (a partir del cual han surgido dos niveles de significado más o menos claros y acusados, uno recto o no fraseológico y otro traslaticio), o bien porque la construcción encierra algún tipo de anomalía léxica (en volandas) y/o sintáctica (a ojos vistas) que no estaría justificada y no tendría sentido en una construcción sintagmática libre.

Así pues, a la idiomaticidad se debe el que, a menudo, en el sistema fraseológico de una lengua, se den dos niveles de significado más o menos claros o diferenciados en relación con una locución en concreto: por un lado, el significado recto, que sería el de la combinación de palabras como sintagma libre: por ejemplo, ponerse las botas como sintagma libre describe la acción de ponerse un tipo determinado de calzado; y, por otro lado, el significado de la locución como tal, esto es, su significado fraseológico (también llamado idiomático o traslaticio), que sería el resultado de una transposición semántica: en este caso, ponerse las botas significa, en una de sus dos acepciones, 'comer mucho en una ocasión determinada, eventualmente con acompañamiento de bebida, y, además, disfrutarlo,4).

De acuerdo con Svensson (2008: 83-87), opinamos que la existencia de dos niveles de significado no siempre coincide con la motivación, ni tampoco con la eventual opacidad o con la analizabilidad de una unidad determinada; la unidad en volandas, por ejemplo, la cual se refiere al modo de ser sujetada y/o transportada una persona o cosa más o menos sin tocar el suelo y con más o menos rapidez (cf. Torrent-Lenzen, en prensa/b), carece de significado recto: en una cadena libre no sería posible el uso de la palabra volandas, ya que ésta no existe como lexema suelto; pero su motivación a partir del verbo volar sí se puede deducir fácilmente. ${ }^{5}$ La motivación constituye un fenómeno más abstracto y más amplio que el significado recto, y acaso pueda definirse como la experiencia

\footnotetext{
4 Nuestra definición en el DEALEE: «aus einem bestimmten Anlass viel essen, eventuell auch viel trinken, und das zudem genießen».

5 Más adelante haremos hincapié en una característica esencial de la naturaleza inferencial de las locuciones, a saber, que ni la motivación ni el significado recto son una garantía para la comprensión del significado fraselógico. En relación con la unidad en volandas, por ejemplo, y después de haber realizado un estudio empírico (cf. TorrentLenzen, en prensa/b), defendemos que volar aquí no sugiere libertad, sino todo lo contrario: apunta hacia el hecho de estar sujetado (o de sujetar) y, a menudo, aunque no siempre, y cuando lo sujetado es una persona, contiene el aspecto semántico de no poder dirigir los pasos hacia donde uno quisiera.
} 
vital y/o la asociación mental que dio pie al proceso de lexicalización y de transposición semántica. El término opacidad se refiere al hecho de que no se pueda comprender el significado fraseológico a partir de los componentes (en volandas, por ejemplo, es una locución opaca) y la analizabilidad se refiere al hecho de si cada componente es analizable en cuanto a su aportación al significado fraseológico (en volandas, por ejemplo, es una locución no analizable). Estos cuatro aspectos enumerados coinciden unas veces, pero otras no.

\subsection{Neutralización y reactualización del acto de referencia}

El proceso de fijación y de lexicalización que ha sufrido toda locución ha conllevado una neutralización de la referencia (cf. Gréciano, 1988: 49) en la gran mayoría de las locuciones. El acto de referencia que normalmente tiene lugar cuando utilizamos palabras como por ejemplo mona o quilo en cadenas sintagmáticas libres deja de tener lugar cuando estas palabras aparecen en una locución, de modo que cuando un hablante manda a alguien a freír monas muy probablemente no se imagina a la otra persona con una sartén en la mano y una mona dentro; ni nos imaginamos una balanza para pesar el sudor cuando decimos que sudaron el quilo. Por esta razón se habla de una neutralización de la referencia y de una transposición semántica: en sudar el quilo, el sintagma el quilo ya no tiene como referente la unidad de peso, sino que significa 'mucho', y la expresión mandar a alguien a freír monas sirve para manifestar desprecio y no describe una acción futura (el acto referencial expresado en dicha cadena de palabras) del receptor del mensaje.

La neutralización de la referencia y la transposición semántica que ésta conlleva son responsables de la opacificación del significado de muchas locuciones. Esto es, el hecho de que no se trate de signos lingüísticos que denotan de manera directa y precisa los convierte a menudo en unidades semánticas imprecisas por naturaleza, sensibles y adaptables al contexto en gran modo (cf. Koller, 2007: 607).

Por supuesto que una locución siempre guarda relación con la imagen o la idea que la motivó. En este sentido, se habla de la reactualización de la referencia que tiene lugar cuando usamos una unidad fraseológica idiomática: de ello nos vamos a ocupar en los apartados siguientes.

\subsection{Implicaturas y connotaciones}

De lo dicho anteriormente se deduce que las locuciones transmiten un contenido de forma implícita. Si con el quilo en la secuencia sudar el quilo el emisor no se refiere a la unidad de peso, ¿cómo sabe el receptor a qué se está refiriendo? En opinión de Gréciano (1987: 144) y de Filatkina (2007: 137), por mencionar solamente a dos autores de los muchos que se han ocupado de este tema, el emisor nos transmite un contenido, el cual no se corresponde con el contenido literal de sus palabras, sobre la base de implicaturas convencionales; el receptor, por su parte, es capaz de descifrar el mensaje a partir de procesos inferenciales. La implicatura convencional de la locución justifica que el receptor infiera otra cosa de lo que dice (cf. Gréciano, 1987: 145-146). En nuestra opinión, por lo 
demás, son también las implicaturas convencionales las que en el caso de las locuciones permiten su significado vago y adaptable al contexto, porque también en casos de gran adaptabilidad contextual podemos observar que se trata de una adaptabilidad relativamente convencionalizada que no afecta la intención del acto de habla.

Gréciano (1987: 144) escribe que la reactualización de la referencia tiene lugar mediante implicaturas conversacionales. Bajo reactualización de la referencia se entiende el fenómeno por el cual los significados de los componentes, después de haber perdido su verdadero significado (neutralización de la referencia), vuelven a «cobrar vida», de modo que cuando usamos una unidad del tipo a toda vela actualizamos hasta cierto punto componentes semánticos marítimos, mientras que a la torera despierta vagas asociaciones relacionadas con las corridas de toros. No obstante, cabe objetar que las implicaturas conversacionales cambian, por definición, según la situación, es decir que es la situación lo que nos permite inferir la intención implícita del emisor en un enunciado, mientras que la reactualización de la referencia en el uso de las locuciones acontece independientemente del contexto. Nosotros tendemos a pensar que la reactualización de la referencia tiene lugar en forma de connotaciones.

\section{Problemas que plantea la definición fraseográfica}

\section{$4.1 \dot{¿}$ Interviene el significado recto en el traslaticio y es ello relevante para la definición?}

Tal como hemos mencionado en el apartado 3.2, en la investigación se parte del hecho de que un buen número de locuciones tienen dos niveles de significado (cf. Ruiz Gurillo, 1997: 99-100; Burger, 2003: 59): el significado recto y el fraseológico, el cual constituye el significado propiamente dicho de la locución como tal; no obstante, un sintagma que tras un proceso de fijación ha dado lugar a una locución siempre queda vinculado en mayor o menor grado al sentido que se desprende de los componentes y a la imagen que estos sugieren; en una palabra: a la idea que ha motivado el proceso de lexicalización (reactualización de la referencia).

Nuestra experiencia en el campo de la fraseografía nos ha hecho llegar a la conclusión de que los diccionarios de español a menudo se basan en exceso en el sentido recto (cf. Torrent-Lenzen / Uría Fernández, 2009). Dicha tendencia se puede observar, por ejemplo, en el diccionario Moliner, obra en la que muchas locuciones son acompañadas del comentario «de significado claro» (véase, por ejemplo, Moliner, 1998: 1185, en relación con la unidad tarde, mal y nunca), solución del todo inadmisible que, entre otras cosas, cuestiona la necesidad misma de que existan obras de consulta. ${ }^{6}$

En general, defendemos que antes de formular una definición sobre el significado fraseológico hay que hacer un análisis muy minucioso de los aspectos semánticos del sentido recto que verdaderamente intervienen en el traslaticio: tal como escribe GarcíaPage (2008: 27), no se trata de una tarea nada fácil. En algunos casos, está plenamente

$6 \mathrm{El}$ aspecto que enfocamos en este apartado está estrechamente relacionado con los temas que tratamos en los apartados siguientes, por lo que el lector encontrará no aquí sino más adelante varios ejemplos que ilustran, de manera crítica, esta tendencia en la fraseografía española. 
justificado dejarse guiar por el significado recto, también en relación con expresiones altamente lexicalizadas. De este modo, nos parece absolutamente correcto que el diccionario Wahrig Deutsches Wörterbuch (2005: 1444) mencione el verbo sehen ('ver') en la definición de zusehends ('por instantes'); en cambio, la acción de 'ver' lógicamente no es mencionada en la definición de por instantes («de manera rápida y progresiva», leemos en Seco et al., 2004: 551), a pesar de que se trata de equivalentes plenos. El punto de convergencia de ambas definiciones sería: de-manera-tan-rápida-y-progresiva-que-inclusose-puede-ver.

\subsection{Interacción y modalidad}

En la definición fraseográfica, un reto especialmente difícil de afrontar lo constituye la diferenciación de las funciones interactiva y modal. Definamos los términos interacción y modalidad citando lo expuesto en Torrent-Lenzen (en prensa/a):

El término interacción se refiere al desarrollo de la conversación y a los mecanismos de intervención y de referencia al cotexto y al contexto que sirven a los intervinientes a la hora de estructurar la actividad comunicativa que están llevando a cabo, de dar más cohesión a la situación y de captar la atención del receptor.

En cambio, con el término modalidad en la lingüística hacemos referencia: «a las interrelaciones, implícitas en gran parte, entre las entidades potenciales básicas que intervienen en la comunicación, esto es, entre emisor, receptor, tema y contexto, y a la actitud del emisor ante una o varias del resto de dichas entidades.» (Torrent-Lenzen, en prensa/a).

A la hora de definir, es importante saber disociar los aspectos interactivos de los modales, saber determinar si una unidad solamente puede usarse en el diálogo o también fuera del mismo: dado que en algunas unidades (del tipo lo que se dice) la interacción siempre está presente en su significado recto, y dado que la modalidad se manifiesta en gran parte en la interacción, esta tarea implica un detallado análisis de los posibles contextos de uso.

Locuciones del tipo no me digas o que me lo digan a mí son interactivas, pues sólo tiene sentido utilizarlas en una conversación. Pero no ocurre así con otras muchas locuciones que tienen el verbo decir o verbos similares como componente principal. Consideremos la unidad a mí que no me digan, que Seco et al. (2004: 364) definen de la siguiente manera: «Se usa para expresar rechazo o incredulidad ante lo que se dice o se insinúa». Opinamos que aquí los autores del DFDEA se han basado en exceso en el significado recto -el cual, en este caso, tiene su origen en la interacción ${ }^{7}-$, pues en los usos reales no es necesario que alguien haya dicho o insinuado algo, tal como muestra el siguiente

En las expresiones formadas sobre la base del verbo decir (a mí que no me digan, lo que se dice, etc.) o verbos similares del tipo contar ha tenido lugar una lexicalización de la polifonía (cf. Torrent-Lenzen, 2009a: 28-29): su origen como locución viene motivado por las voces que intervienen en la interacción, de acuerdo con la teoría de Ducrot (1984). 
ejemplo: ${ }^{8}$ 1) Tantos y tantos recuerdos tiene uno asociados al rollo este de la Navidad (porque es un rollo, a mí que no me digan), que cuesta pasar de largo sin hacer lo que hacen todos: mandar felicitaciones, comprar regalos, etc.

Por el contrario, en la definición de tira y afloja leemos en Seco et al. (2004: 975) «rigor y condescendencia alternados», definición que nos parece del todo equívoca y que también se basa en exceso en la información que transmiten los dos componentes tira y afloja, puesto que no da cuenta en absoluto de que esta locución implica una situación interactiva muy intensa.

\section{3 Único método fiable: el análisis del contexto}

Sobre todo en relación con locuciones altamente idiomáticas, no es posible acceder al significado de una locución a partir de la mera cadena de palabras que la conforman, puesto que, por más clara que sea su motivación, su significado traslaticio no es necesariamente deducible. Sólo existe la posibilidad de recurrir a un análisis detallado de todos los elementos que configuran el contexto. Por lo tanto, sólo es posible acceder a los significados traslaticios mediante las herramientas terminológicas y analíticas de la lingüística pragmática.

Ello implica, a la hora de averiguar el significado de una locución y de intentar definirla lo más exactamente posible en un diccionario, la necesidad de trabajar con ejemplos auténticos y espontáneos, en los que el emisor no haya pretendido ni demostrar significados (éste es uno de los problemas de los ejemplos inventados) ni experimentar con la lengua (inconveniente que se da en muchos textos literarios y periodísticos). Pero, además, los ejemplos deberán ser definitorios, lo cual significa que deberán ofrecer un contexto mínimo analizable.

Vamos a centrarnos, a continuación, en las unidades directo a la yugular y por el amor de Dios: el análisis de estas locuciones ilustrará la importancia del trabajo con ejemplos auténticos, espontáneos y definitorios, así como lo expuesto en los apartados anteriores. Consideremos la locución directo a la yugular. El DFDEA ofrece la siguiente definición: «directo a la yugular. $a d v$ Atacando violentamente con intención de causar un grave daño» (Seco et al., 2004: 1056). Es cierto que existe una acepción en este sentido, cuya motivación hay que buscarla en el hecho de que ciertos animales matan a sus víctimas mordiéndoles la vena yugular; la pertinencia de la definición de Seco et al. (2004: 1056) se puede comprobar fácilmente analizando numerosos ejemplos que aparecen en la red: 2) fue un ataque personal y directo a la yugular; 3) la política del PP es directo a la yugular... da igual lo que sea... primero ataca y luego remata. No obstante, en Internet esta locución también aparece frecuentemente en contextos que no justifican esta definición, ni mucho menos la información de «con intención de causar un grave daño»:

8 En el presente artículo nos servimos de ejemplos procedentes o bien de Internet o bien del material reunido para el DEALEE. En el DEALEE trabajamos mayormente con ejemplos procedentes de la red, pero normalmente los retocamos (introducimos correcciones, etc.) a fin de hacerlos traducibles, y dado el carácter didáctico que tiene todo diccionario, sobre todo si es bilingüe. Por esta razón, en el presente artículo sólo vamos a indicar la página web de donde proceden los ejemplos cuando estos los hayamos buscado ad hoc para realizar este estudio: se trata, en concreto, de los ejemplos reunidos para llegar a conclusiones sobre el significado de tomar el portante. 
4) el gusanillo de la curiosidad me atacó (directo a la yugular); 5) Destila creatividad por los cuatro costados, te deja sin aliento, va directo a la yugular; 6) Un humor no sé si inteligente (etiqueta muy abusada) pero sí muy divertido y directo a la yugular. Me ha levantado el ánimo alicaído que tenía estos días; 7) Directo a la yugular. No te deja indiferente [como comentario a un película]; 8) Tenemos si se puede decir un rock crudo, muy directo a la yugular, y pasional o mejor dicho visceral. Si analizamos lo que tienen los ejemplos 4 a 8 en común, veremos que el protagonista de la acción se ve afectado de manera directa, incisiva e intensa; la persona afectada, además, no tiene nada en contra de verse afectada con tanta intensidad; antes bien: en la gran mayoría de los casos lo disfruta enormemente. En nuestra opinión, la unidad directo a la yugular tiene dos acepciones: una de ellas se obtiene a partir de ejemplos del tipo 2 y 3 ; la otra la ganamos a partir del análisis de ejemplos del tipo 4 a 8 .

El estudio de los significados de la unidad directo a la yugular demuestra que no es suficiente dejarse guiar por la motivación o por el significado recto, aunque éstos sean muy importantes. La motivación explica las pautas que han canalizado el pensamiento humano a la hora de crear nuevo material noético y lingüístico -y acaso a la hora de procesarlo (cf. Omazić, 2008: 69)-. Pero no se trata del significado traslaticio en sí.

Vamos a considerar ahora la locución por el amor de Dios, que en nuestra opinión no es equivalente a la unidad alemana um Gottes Willen, o, si lo es, en todo caso sólo muy parcialmente, si bien el lector podrá encontrar en numerosos diccionarios bilingües esta supuesta equivalencia. $\mathrm{Al}$ respecto queremos presentar un ejemplo escuchado por nosotros mismos. Dos profesores estaban hablando y uno de ellos se quejó de la pasividad de sus colegas del mundo de la enseñanza diciendo: 9) Si no se dan las condiciones necesarias, pues, por el amor de Dios: ¡créalas! El emisor, mediante el uso de la locución, refuerza el acto de habla de la exhortación expresada en el imperativo, a la vez que lo atenúa por el hecho de representar un ruego (cf. Seco et al. 2004: 140). En cambio, con la locución alemana um Gottes Willen, el emisor manifiesta otro tipo de estados emotivos, por regla general indignación o sorpresa de signo negativo: 10) Um Gottes Willen, jetzt fällt mir ein, dass ich den Wasserhahn nicht zugedreht habe!; rechazo o negación rotunda ante lo que ha dicho o insinuado otra persona: 11) Um Gottes Willen! In so eine Schrottkarre würde ich nie einsteigen!, etc. En el ejemplo auténtico presentado en español la locución alemana sería inviable. ${ }^{9}$

Desde un punto de vista diacrónico, en la locución alemana ha tenido lugar un proceso de gramaticalización de más alcance que en la unidad española, probablemente a partir de estructuras del tipo Um Gottes Willen nicht!, de modo que ha pasado a expresar lo que no se desea, mientras que con el uso de la unidad española el emisor expresa lo que desea. De nuevo vemos que sólo un análisis pragmático de los contextos de uso nos permite llegar al significado traslaticio de las locuciones, mientras que la imagen base que ha dado pie al proceso de gramaticalización nos informa únicamente sobre el mecanismo noético de formación.

9 Véase en Torrent-Lenzen (en prensa/c) un estudio más detallado con ejemplos auténticos procedentes de la red de las unidades um Gottes Willen y por el amor de Dios. 
En estrecha relación con el tema de los ejemplos auténticos surge la cuestión de las fuentes adecuadas que los pueden proporcionar. Los fraseologismos tienen un significado poco transparente, por lo que se hace necesario trabajar con corpus (cf. Lemnitzer; Zinsmeister, 2006: 150). Podemos afirmar que nuestro trabajo de elaboración del DEALEE es corpus based y corpus driven a la vez; esto es, nosotros tenemos una idea de lo que significa una locución a partir de nuestro saber como hablantes nativos y de la información que figura en las obras de consulta, saber que intentamos corroborar basándonos en ejemplos de un corpus; pero, por otra parte, y ésta es la más importante, son los ejemplos auténticos los que tienen la última palabra sobre el significado de las locuciones, los que nos dicen y demuestran si estábamos en lo cierto o no. Este método nos parece esencial a la hora de definir locuciones. A este respecto, y en relación con la investigación de los sistemas fraseológicos, vale decir que entre tanto estamos convencidos de la absoluta necesidad de trabajar con Internet y de observarlo como un corpus. ${ }^{10}$

\subsection{Tomar el portante no es simplemente 'marcharse': el valor semántico adicional de las locuciones}

A la hora de enfrentarnos con la información implícita que incluyen las locuciones nos basamos en gran parte en el estudio de Kühn (1985) sobre el llamado valor semántico adicional de las locuciones. Según Kühn (1985), las locuciones contienen información sobre la actitud del emisor que no suelen contener los supuestos sinónimos no fraseológicos que ofrecen los diccionarios. Vamos a ejemplificar el valor semántico adicional que contienen las locuciones a partir de la unidad tomar el portante, la cual es definida en Seco et al. (2004) de la siguiente manera: «Irse o marcharse. Frec usado expletivamente» (Seco et al., 2004: 821). No obstante, oraciones del tipo ?Creo que es mejor que tomes el portante por la mañana no suenan muy auténticas, si bien no puede afirmarse rotundamente que representen usos incorrectos. Veamos a continuación, algunos ejemplos auténticos procedentes de Internet: 12) algún día agarraría el portante y se emanciparía; ${ }^{11} 13$ ) Mi fobia a las cucarachas es fuera de serie, o sea, que como yo vea una sola de ellas donde sea cojo el portante y me voy por patas; ${ }^{12} 14$ ) juraba con una horrible blasfemia que tomaría el portante y se lanzaría a nada bueno si volvían a hablar de ello; ${ }^{13}{ }^{15}$ ) El día menos pensao cojo el portante y ahí te quedas, guapita, y no pienses que te voy a pasar una paguita to los meses para que estés como una reina; ${ }^{14}$ 16) $Y$ si en un trabajo por muy bien que me paguen, no estoy bien por cualquier motivo... cojo el portante y me piro!: ${ }^{15}$ 17) Ella por suerte cuando se cansó de tanta estupidez agarró el portante y dijo «paso»,

\footnotetext{
${ }^{10}$ No ha sido hasta la primera década del siglo XXI que los lingüistas han descubierto Internet como fuente de datos lingüísticos; Mukherjee (2009: 20) recalca la importancia de la red, puesto que ofrece datos para fenómenos que no aparecen en otros corpus más selectivos.

11 www.scribd.com/doc/.../Bosch-Alfred-El-Atlas-Furtivo.

12 aalinne-xlokmda.blogspot.com.

13 sobrefulanos.blogspot.com/2009_10_29_archive.html.

14 www.fotolog.com/kaskete/36393472.

15 andapez.blogspot.com/2007/09/merece-la-pena-vivir-para-trabajar.html.
} 
se levantó y desapareció del mapa. ${ }^{16}$ Obsérvese que en todos estos ejemplos (12 a 17) intervienen emociones, las cuales empujan al protagonista a tomar la decisión de irse. En la red hemos encontrado también algunos ejemplos en los que no intervienen emociones especialmente fuertes o negativas: 18) En el verano de 1996, un equipo de Gestmusic cogió el portante y se fue en busca de talentos desconocidos por toda la geografía española ${ }^{17}$ 19) lo mismo cojo el portante y me pego el viaje, que ganas tengo; $\left.{ }^{18} 20\right)$ Semana tras semana tomábamos el portante y recorríamos por los medios más variados (autobús sobre todo) los cien escasos kilómetros que separan Pamplona de la mítica ciudad del vino y los pimientos. ${ }^{19}$ No obstante, aunque no intervengan emociones negativas, estos ejemplos (18 a 20) tienen en común con los anteriores (12 a 17) el hecho de que el emisor acentúa, de modo bastante claro, el haber tomado una decisión: pensamos que es ésta la explicación de la construcción sintáctica «tomar el portante + sintagma verbal», de la que Seco et al. (2004: 821) intentan dar cuenta mediante el concepto de la «expletividad», uno de los más criticados en la lingüística porque no hace sino apuntar hacia déficits analíticos, si bien por cuestiones prácticas todos seguimos haciendo uso del mismo.

De acuerdo con los ejemplos auténticos reunidos, en el DEALEE hemos formulado la siguiente entrada:

coger el portante una persona (verb. Ph.; ugs.; VAR.: agarrar [oder tomar] el portante una persona; i. d. R. und vor allem bei coger und agarrar folgt dieser Wendung die Struktur $y$ + ein Verb des Weggehens): weggehen, meistens als punktuelle, bewusste Handlung bzw. Entscheidung, die oftmals mit Emotionen (Verärgerung, Langweile, Enttäuschung o. Ä.) von seiten des Handelnden verbunden ist. Si en un trabajo, por muy bien que me paguen, no estoy bien por cualquier motivo... cojo el portante y me piro. Wenn ich mich bei einem Job aus irgendeinem Grund nicht wohlfühle, ist es völlig egal, wieviel sie mir dort bezahlen - ich packe meine sieben Sachen und Tschüss! Mi fobia a las cucarachas es fuera de serie, como yo vea una sola de ellas donde sea cojo el portante y me voy por patas. Meine Kakerlakenphobie ist außergewöhnlich stark ausgeprägt. Sobald ich auch nur eine einzige Kakerlake sehe, bin ich schneller weg, als man gucken kann. El día menos pensado cojo el portante y ahí te quedas, guapita, y no pienses que te voy a pasar una paguita todos los meses para que estés como una reina. Eines Tages, wenn du es am wenigsten erwartest, packe ich meine sieben Sachen und mache mich auf und davon. Und dich, mein Liebchen, dich lasse ich sitzen. Und glaube bloß nicht, dass ich dir jeden Monat ein feines Sümmchen zukommen lasse, damit du in Saus und Braus leben kannst. ${ }^{20}$

Obsérvese que en las traducciones al alemán, intentamos reproducir el mismo esquema noético-emotivo a base de introducir sintagmas coordinados del tipo ich packe meine sieben Sachen und Tschüss!, los cuales, entre otras cosas, respetan el ritmo del original.

\footnotetext{
16 gente5.telecinco.es/.../me-merecia-una-segunda-oportunidad/?.

17 www.gestmusic.es/programa/sonrisasdeespana/?id=1.

18 cn.last.fm/user/oneblackday/shoutbox.

19 http://www.opuslibros.org/escritos/perdiendo_antrax.htm.

${ }^{20}$ La definición en español rezaría: «irse, normalmente como acción o decisión puntual y consciente, que a menudo viene relacionada con emociones (enfado, aburrimiento, decepción, etc.) por parte de la persona que actúa».
} 


\section{El papel de la pragmática en la fraseología y en la fraseografía}

Como colofón a nuestras reflexiones, vamos a comentar la definición de la unidad tarde, mal y nunca, ya mencionada más arriba, tal como figura en la segunda edición del DUE: en dicho diccionario el usuario puede leer que se trata de una «expresión de significado claro» (Moliner, 1998 II: 1185; véase también Alvar Ezquerra, 2000: 244). A nuestro parecer, esta afirmación es del todo incorrecta, puesto que entre los componentes incluso se da un significado contradictorio: lo que ha ocurrido tarde y mal no es posible que no haya ocurrido nunca. En ejemplos como el siguiente queda claro que la unidad tarde, mal y nunca significa 'mucho más tarde de lo deseado o conveniente': 21) Al contrario que el Holocausto judío, el Estado alemán ha reaccionado con respecto al exterminio de los gitanos tarde, mal y nunca, no reconociendo su responsabilidad y culpa. Simon Wiesenthal, en un acto de reconocimiento al pueblo gitano, recordó, en 1984, que el $80 \%$ de los gitanos que fueron apresados por los nazis murieron en los campos de concentración o fueron asesinados por unidades especiales, un porcentaje casi idéntico al de la población judía exterminada. ${ }^{21}$ Moliner (1998 II: 1185) añade, por lo demás, que se trata de una «queja o comentario de la manera de hacer alguien cierta cosa». No estamos de acuerdo con esta afirmación; en todo caso, nos encontramos ante una locución adverbial que aparece en un contexto en el que el emisor se queja, pero la locución en sí no es una queja, porque una queja implica un enunciado, y la unidad tarde, mal y nunca no suele formar un enunciado por sí sola.

Penadés Martínez (1999: 198) escribe con razón que existe un desajuste entre la práctica lexicográfica y las aportaciones de las distintas disciplinas lingüísticas, sobre todo de la pragmática, de tradición más bien corta. No podemos sino corroborar este hecho con el saber que estamos adquiriendo a partir de la elaboración del DEALEE. También Kühn (1994) recalca que el análisis pragmático conlleva consecuencias importantes para la fraseografía.

\section{Conclusión}

En el presente artículo hemos defendido que algunos aspectos esenciales del significado de las locuciones sólo son analizables desde el punto de vista de la lingüística pragmática, entre otras cosas porque se trata de signos lingüísticos con un enorme potencial semántico contextual e inferencial. Para que un análisis pragmático sea posible se necesitará material fidedigno; esto es, corpus no selectivos con ejemplos auténticos, espontáneos y definitorios, a partir de los cuales el fraseógrafo podrá llegar a conclusiones sólidas sobre el significado y la fomulación de definiciones.

A la hora de determinar el significado de una locución y de formular una definición lexicográfica hay que tener en cuenta, entre otras cosas, aspectos como la actitud del emisor o de otros intervinientes en la situación, así como eventuales elementos modales y/o interactivos. Igualmente, será útil analizar y cuestionar en cada caso hasta qué punto

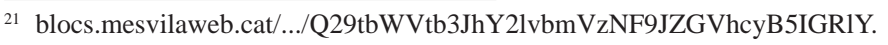


cabe integrar en la definición componentes semánticos que se desprenden del significado recto o de la motivación.

\section{BIBLIOGRAFÍA}

Alvar Ezquerra, M. (2000): «Unidades fraseológicas definidas como de sentido o significado claro en el diccionario de María Moliner». En: Corpas Pastor, G. (ed.), Las lenguas de Europa: estudios de fraseología, fraseografía y traducción. Granada: Comares, 231-248.

Beßler, J.; Erkelenz, M.; Marín Martínez, M. T.; Torrent-Lenzen, A.; Uría Fernández, L. (2009): «Presentación del proyecto Diccionario español-alemán de locuciones del español de España de Colonia/Hamburgo». En: Kooperativer Hochschulschriftenserver NRW (KOPS); Online Publikationsverbund der Universität Stuttgart. En: <http://opus.bibl.fh-koeln.de/ volltexte/2009/199/pdf/Proyecto_diccionario_locuciones.pdf.> (4. 11. 2010)

Bosque, I.; Gutiérrez-Rexach, J. (2009): Fundamentos de sintaxis formal. Madrid: Akal.

Burger, H. (2003): Phraseologie. Eine Einführung am Beispiel des Deutschen. Berlin: Erich Schmidt Verlag.

DFDEA = Seco, M.; Andrés, O.; Ramos, G. (2004): Diccionario fraseológico documentado del español actual. Locuciones y modismos españoles. Madrid: Aguilar.

Dobrovol'skij, D. O. (1988): Phraseologie als Objekt der Universalienlinguistik. Leipzig: Enzyklopädie.

Ducrot, O. (1984): Le dire et le dit. Paris: Les Éditions de Minuit.

DUE = Moliner, M. (21998 [11966-1967]): Diccionario de uso del español. Madrid: Gredos. (DUE).

Filatkina, N. (2007): «Pragmatische Beschreibungsansätze». En: Burger, H.; Dobrovolskij, D. O.; Kühn, P.; Norrick, N. R. (eds.), Phraseologie - ein internationales Handbuch zeitgenössischer Forschung. Vol. 1. Berlin: de Gruyter, 132-158.

García-Page Sánchez, M. (2008): Introducción a la fraseología española. Estudio de las locuciones. Barcelona: Anthropos.

Gréciano, G. (1987): «Les inférences de l'idiome». En: Riegel, M. (ed.), L'implication dans les langues naturelles et dans les langages artificiels. Strasbourg: TRALILI. París: Klincksieck, 139-153.

Gréciano, G. (1988): «Affektbedingter Idiomgebrauch». En: Sandig, B. (ed.), Stilistisch-rhetorische Diskursanalyse. Tubinga: Narr, 49-61.

Grzybek, P. (2007): «Semiotische Aspekte der Phraseme». En: Burger, H.; Dobrovolskij, D. O.; Kühn, P.; Norrick, N. R. (eds.), Phraseologie - ein internationales Handbuch zeitgenössischer Forschung. Vol. 1. Berlin: de Gruyter, 188-208.

Koller, W. (2007): «Probleme der Übersetzung von Phrasemen». En: Burger, H.; Dobrovolskij, D. O.; Kühn, P.; Norrick, N. R. (eds.), Phraseologie - ein internationales Handbuch zeitgenössischer Forschung. Vol. 1. Berlin: de Gruyter, 605-613. 
Kühn, P. (1985): «Phraseologismen und ihr semantischer Mehrwert». En: Sprache und Literatur in Wissenschaft und Unterricht 56, 37-46.

Kühn, P. (1994): «Pragmatische Phraseologie: Konsequenzen für die Phraseographie und Phraseodidaktik». En: Sandig, B. (ed.), Europhras 92: Tendenzen der Phraseologieforschung. Bochum: Universitätsverlag Brockmeyer, 411-428.

Lemnitzer, L.; Zinsmeister, H. (2006). Korpuslinguistik. Tübingen: Gunter Narr.

Mukherjee, J. (2009): Anglistische Korpuslinguistik. Eine Einführung. Berlin: Erich Schmidt Verlag.

Omazić, M. (2008): «Processing of idioms and idiom modifications. A view from cognitive linguistics». En: Granger, S.; Meunier, F. (eds.), Phraseology. An interdisciplinary perspective. Amsterdam; Philadelphia: John Benjamins Publishing Company, 67-79.

Penadés Martínez, I. (1999): «Para un tratamiento lexicográfico de las expresiones fijas irónicas desde la pragmática». En: Pragmalingüística 7, 185-210.

Ruiz Gurillo, L. (1997): Aspectos de fraseología teórica española. Valencia: Universitat de València, Cuadernos de Filología, Anejo 24.

Svensson, M. H. (2008): "A very complex criterion of fixedness: Non-compositionality». En: Granger, S.; Meunier, F. (eds.), Phraseology. An interdisciplinary perspective. Amsterdam; Philadelphia: John Benjamins Publishing Company, 81-93.

Torrent-Lenzen, A. (2009/a): «Polifonía de las emociones. Estudio pragmático sobre la función emotiva de las partículas modales en castellano, catalán y rumano». En: Estudis Romànics 31, Barcelona, 7-34.

Torrent-Lenzen, A. (2009/b): «Lema, categoría y definiens en la fraseografía monolingüe del español y bilingüe español-alemán». En: Cadernos de Fraseoloxía Galega 11, 229-256.

Torrent-Lenzen, A. (en prensa/a): «Las locuciones marcadoras construidas sobre la base del verbo decir: aspectos fraseográficos y traslaticios (español-alemán)». En: Loureda, Ó. et al. (eds.), Actas del Congreso de las Sociedad Alemana de Hispanistas, Tübingen 2009. IberoamericaVervuert.

Torrent-Lenzen, A. (en prensa/b): «Tiempo, espacio y volición. Estudio de los significados de la locución en volandas desde el punto de vista de la fraseografía bilingüe español-alemán». En: Montoro del Arco, E. T.; Sinner, C.; Tabares Plasencia, E. (eds.), Tiempo, espacio y relaciones espacio-temporales en la fraseología y paremiología española. München: Peniope.

Torrent-Lenzen, A. (en prensa/c, 2010): «Las locuciones emotivas en español y su correspondencia al alemán (con un análisis contrastivo de las unidades por el amor de Dios y um Gottes Willen)». En: Neuere Studien zur angewandten kontrastiven Linguistik Deutsch-SpanischPortugiesisch. Stuttgart: Ibidem Verlag.

Torrent-Lenzen, A.; Uría Fernández, L. (2009): «Los niveles de significado recto y traslaticio en el Diccionario fraseológico documentado del español actual de Seco et al.». En: Lingüística en la Red (LinRed), 05.02.2009, 1-24. <http://www.linred.com/articulos_pdf/LR_ articulo_28012009.pdf> Wahrig Deutsches Wörterbuch (2005). Gütersloh; München: Wissen Media Verlag. (4. 11. 2010) 


\section{TOMAR EL PORTANTE NE POMENI ZGOLJ ‘ODDITI’: RAZMIŠLJANJA O OPREDELITVI FRAZEOLOŠKO-IDIOMATSKIH ENOT V SLOVARJIH S PRAGMATIČNEGA VIDIKA}

Ključne besede: frazeografija, pragmática, interakcija, modalnost, poenostavitev, korpus

Avtorica članka obravnava osnovne probleme, s katerimi se sreča frazeograf pri opredeljevanju frazeološko-idiomatskih enot, ki jih zaznamuje nejasen ter v večini primerov tudi pogojni pomen. Izhaja iz stališča, da se lahko nekateri osnovni aspekti pomena stalnih besednih zvez (kot na primer odnos izjavljalca ali pa eventuelni interaktivni ter modalni elementi) analizirajo zgolj s pragmatičnega vidika, predvsem zaradi dejstva, da gre za jezikovne znake $\mathrm{z}$ intenzivnim kontekstualnim in inferencialnim potencialom. Poleg tega pa so za pragmatično analizo nujni neselektivni korpusi avtentičnih primerov, na podlagi katerih se frazeograf lahko dokoplje do opredelitev in zaključkov glede njihovih pomenov. 